\title{
Overweight and Decreased Baroreflex Sensitivity as Independent Risk Factors for Hypertension in Children, Adolescents, and Young Adults
}

\author{
K. KRONTORÁDOVÁ ${ }^{1}$, N. HONZÍKOVÁ ${ }^{2}$, B. FIŠER ${ }^{2}$, Z. NOVÁKOVÁ ${ }^{2}$ E. ZÁVODNÁ \\ H. HRSTKOVÁ ${ }^{1}$, P. HONZÍK ${ }^{3}$
}

${ }^{1}$ First Department Paediatric Internal Medicine and ${ }^{2}$ Department of Physiology, Faculty of Medicine, Masaryk University, Brno, and ${ }^{3}$ Department of Control and Instrumentation, Brno University of Technology, Brno, Czech Republic

Received March 21, 2007

Accepted April 20, 2007

On-line May 30, 2007

\begin{abstract}
Summary
We studied the relationship between blood pressure (BP), body mass index (BMI, $\mathrm{kg} / \mathrm{m}^{2}$ ) and baroreflex sensitivity (BRS, $\mathrm{ms} / \mathrm{mmHg}$ ) in adolescents. We examined 34 subjects aged $16.2 \pm 2.4$ years who had repeatedly high causal $B P(H)$ and 52 controls $(C)$ aged $16.4 \pm 2.2$ years. Forty-four $\mathrm{C}$ and $22 \mathrm{H}$ were of normal weight (BMI between 19-23.9), and $8 \mathrm{C}$ and $12 \mathrm{H}$ were overweight (BMI between 24-30). Systolic BP was recorded beatto-beat for 5 min (Finapres, controlled breathing $0.33 \mathrm{~Hz}$ ). BRS was determined by the cross-spectral method. The predicting power of BMI and BRS for hypertension was evaluated by sensitivity, specificity, and receiver operating curve (ROC - plot of sensitivity versus specificity). $\mathrm{H}$ compared with $\mathrm{C}$ had lower BRS $(p<0.01)$ and higher BMI $(p<0.05)$. Multiple logistic regression analysis $(p<0.001)$ revealed that a decreased BRS $(p<0.05)$ and an increased BMI $(p<0.01)$ were independently associated with an increased risk of hypertension. No correlation between BMI and BRS was found either in $\mathrm{H}$ or in C. Following optimal critical values by ROC, the sensitivity, specificity and area under ROC were determined for: BMI - $22.2 \mathrm{~kg} / \mathrm{m}^{2}, 61.8 \%, 69.2 \%$, $66.0 \%$; BRS - $7.1 \mathrm{~ms} / \mathrm{mmHg}, 67.7 \%, 69.2 \%, 70.0 \%$; BMI and BRS - 0.439 a.u., $73.5 \%, 82.7 \%$, and $77.3 \%$. Decreased BRS and overweight were found to be independent risk factors for hypertension.
\end{abstract}

\section{Key words}

Baroreflex sensitivity • Blood pressure • Overweight •

Hypertension • Adolescents

\section{Corresponding author}

Nataša Honzíková, Department of Physiology, Faculty of Medicine, Masaryk University, Komenského nám. 2, 66243 Brno, Czech Republic. Fax: +420 549493748 . E-mail: nhonziko@med.muni.cz

\section{Introduction}

Essential hypertension is a common cardiovascular disease in adults. Its prevalence is about $20 \%$ and it increases with age. Essential hypertension is not a frequent diagnosis in childhood or during adolescence, but its later development could originate at these stages (Vos et al. 2003).

Baroreflex is a mechanism involved in short-term and long-term blood pressure control. Baroreflex sensitivity (BRS) is an index of the autonomic baroreflex control of the heart rate. It has been shown that BRS decreases with age in adults (Gribbin et al. 1971, Kardos et al. 2001). Though BRS can reach resting values between 2 and $30 \mathrm{~ms} / \mathrm{mmHg}$ in adults and the resting value of BRS fluctuates (Honzíková et al. 2003), it is an individually reproducible index. Considering the wide intra-subject variability of different measures of resting BRS, caution should be exercised against over-interpretation of minor differences, as Bene et al. (1999) showed by testing 12 subjects. On the other hand, the reproducibility of BRS measured in a larger group of 116 subjects indicated that BRS is an individual characteristic feature with the highest reproducibility at its low values in spite of its resting variation (Jíra et al. 2006a).

Studies of physiological BRS values in children and adolescents have also been published. These studies indicate that values of BRS are similar to those of healthy adults and that interindividual differences are also very large. Very different values of BRS were reported in 1868 children (10-13 years old) by Dietrich et al. (2006) - 
between 2.3 and $73 \mathrm{~ms} / \mathrm{mmHg}$; smaller differences were found in a group of 415 subjects 11-20 years old by Závodná et al. (2007). These differences ranged from $3.9 \mathrm{~ms} / \mathrm{mmHg}$ for the 5 th percentile and $18.7 \mathrm{~ms} / \mathrm{mmHg}$ for the 95th percentile. These are important findings from the point of view of cardiology, since it has been reported that BRS is usually less than $5 \mathrm{~ms} / \mathrm{mmHg}$ in hypertensive patients (Lábrová et al. 2005) and that BRS lower than $3 \mathrm{~ms} / \mathrm{mmHg}$ is a marker of an increased risk of sudden cardiac death in patients after myocardial infarction (La Rovere et al. 1998, Honzíková et al. 2000).

Recently, evidence has been accumulating which suggests that BRS decreases with thickening of the carotid wall (Zancheti et al. 1998, Lábrová et al. 2005, Honzíková et al. 2006a). A correlation between carotid artery stiffness and age in young adults has also been reported (Urbina et al. 2004). On the other hand, interindividual differences of BRS in healthy subjects may be due to heredity (Kardos et al. 2001). Previous human studies provided estimates of the genetic effect on BRS indirectly. Normotensive and borderline hypertensive subjects with a family history of hypertension exhibited a decrease in BRS compared with normotensive controls without a family history of hypertension (Iwase et al. 1984). BRS heritability was assessed also in a study of monozygotic and dizygotic twin pairs (Tank et al. 2001). More recent genetic studies support the opinion that variants in genes may be responsible for the great range in baroreflex function observed in humans and that such variation may play a role in the development of hypertension (Gollasch et al. 2002).

Besides low BRS, another important risk factor for hypertension is obesity. The Framingham study found that the prevalence of hypertension in obese individuals was twice that among individuals of normal weight, across all ages in men and in women (Hubert et al. 1983). Several studies have also reported that weight loss in hypertensive subjects lowered blood pressure (Gordon et al. 1997, Kriketos et al. 2001). Obesity and body fat distribution were also found to elevate ambulatory blood pressure in children in a previous study (Lurba et al. 1988).

Though obesity and low BRS have consistently been shown to be associated with hypertension, the hypothesis that a genetically determined predisposition toward low BRS and overweight could dispose a subject to essential hypertension additively has not been adequately investigated. In the present study we analyzed whether body mass index and baroreflex sensitivity are two independent factors associated with elevation of blood pressure in children, adolescents, and young adults.

\section{Methods}

\section{Subjects}

Subjects with essential hypertension were recruited from patients examined in practical ambulatory pediatrics centers. To be selected for inclusion into the group of young subjects designated as having elevated blood pressure, male and female children, adolescents and young adults aged 11-21 years had to have office average sitting systolic and diastolic blood pressures higher than the value of blood pressure for the 95th percentile of blood pressure at three consecutive measurements taken in the interval of at least 1 week. The applied value of the 95th percentile respected age, sex and height, i.e. for boys and girls aged 11 to 17 years the values of the Task Force Report on blood pressure control in children (1996) were used, and for subjects aged 18 years and older the critical value of $140 / 90 \mathrm{mmHg}$ was used. Thirty-four subjects (22 boys, 12 girls) of 11-21 years of age (mean age 16.2 \pm 2.4 years) were recruited. In these subjects, $24 \mathrm{~h}$ ambulatory blood pressure monitoring was obtained and in 18 of the subjects, whitecoat hypertension was observed. Any form of secondary hypertension was ruled out by routine clinical examination.

Fifty-two healthy controls ( 24 boys, 28 girls) in corresponding age groups (mean age $16.4 \pm 2.2$ years) were recruited from three schools (basic and high schools, and University) in the city of Brno. In total, 86 subjects were examined. The study was approved by the Ethical Committee. All participants in the study and their parents received information letters about the study. All subjects 18 years of age or older gave their written consent; the written consent of those younger than 18 years was given by the parents of the subjects.

\section{Body mass index}

Body weight and height were measured and the body mass index (BMI) was calculated for every subject. Forty-four controls and 22 hypertensive patients were of normal weight (BMI between 19-23.9), and 8 controls and 12 hypertensive patients were overweight (BMI between 24-30).

\section{Blood pressure monitoring}

Blood pressure monitoring was carried out (Space Labs Medical, ABP Monitor 90217, 90207, Redmond, WA, USA) in subjects who were recruited as hypertensive subjects in practical ambulatory pediatrics centers. The 
Table 1. Differences between healthy controls and hypertensive patients.

\begin{tabular}{llll}
\hline Parameter & $\begin{array}{l}\text { Controls } \\
(\mathbf{n}=\mathbf{5 2})\end{array}$ & $\begin{array}{l}\text { Hypertensive } \\
\text { subjects }(\mathbf{n}=\mathbf{3 4})\end{array}$ & $\begin{array}{l}\text { Statistical significance } \\
\text { (Mann-Whitney test) }\end{array}$ \\
\hline Age (years) & $16.4 \pm 2.2$ & $16.1 \pm 2.4$ & $\mathrm{~ns}$ \\
BMI $\left(\mathrm{kg} / \mathrm{m}^{2}\right)$ & $21.8 \pm 2.2$ & $23.2 \pm 2.8$ & $\mathrm{p}<0.05$ \\
Systolic/diastolic $(\mathrm{mmHg})^{*}$ & $110 / 66 \pm 10 / 9$ & $125 / 71 \pm 14 / 9$ & $\mathrm{p}<0.001 / \mathrm{p}<0.05$ \\
BRS $\left(\mathrm{ms} / \mathrm{mmHg}^{2}\right)$ & $10.4 \pm 6.1$ & $6.8 \pm 3.4$ & $\mathrm{p}<0.01$ \\
\hline
\end{tabular}

BMI - body mass index, BRS - baroreflex sensitivity, * - Finger blood pressure

Table 2. Sensitivity and specificity of baroreflex sensitivity (BRS), body mass index (BMI), and combination of both factors for hypertension calculated for optimal critical values, and area under receiver operating curve of these indices of risk for hypertension.

\begin{tabular}{llll}
\hline $\begin{array}{l}\text { Parameter } \\
\text { (optimal critical value) }\end{array}$ & Sensitivity [ \%] & Specificity [ \%] & $\begin{array}{l}\text { Area under receiver } \\
\text { operating curve [ \%] }\end{array}$ \\
\hline$B R S(7.08 \mathrm{~ms} / \mathrm{mmHg})$ & 67.7 & 69.2 & 70.0 \\
$B M I\left(22.2 \mathrm{~kg} / \mathrm{m}^{2}\right)$ & 61.8 & 69.2 & 66.0 \\
$B M I$ and $B R S(0.439$ a.u. $)$ & 73.5 & 82.7 & 77.3 \\
\hline
\end{tabular}

BMI - body mass index, BRS - baroreflex sensitivity

monitoring device was programmed to take a blood pressure measurement every $15 \mathrm{~min}$ from 6 to $22 \mathrm{~h}$ (daytime) and every $20 \mathrm{~min}$ from 22 to $6 \mathrm{~h}$ (night-time). The monitoring cuff was applied around the non-dominant arm in the morning. Subjects went home and they were asked to continue their regular activities, but not to move the monitored arm during each automatic blood pressure measurement. For each $24 \mathrm{~h}$ blood pressure monitoring, the calculation included 24 hours, day, night, and hourly averages for diastolic blood pressure and systolic blood pressure. The day and night averages were calculated between 8 and $20 \mathrm{~h}$ and between 24 and $6 \mathrm{~h}$, respectively, in order to eliminate transitional periods in which wakefulness or sleep was unclear. The subjects were included in the group of hypertensive patients when $40 \%$ of the values of systolic and/or diastolic blood pressure measured during day and/or night were higher than the 95th percentile of the values for height (Soergel et al. 1997). Those having lower blood pressure than taken as the limit for hypertension, i.e. those with white-coat hypertension, were also included in the statistical group designated as having elevated blood pressure.

Continuous blood pressure measurement and baroreflex sensitivity determination

Indirect continuous 5-min blood pressure recordings from finger arteries (Finapres, Ohmeda, Madison, USA) were performed in sitting, resting subjects between 9 a.m. and noon. The recordings were taken during spontaneous and synchronized breathing. During the latter, only the rhythm of breathing was controlled at 20 breaths per min by metronome $(0.33 \mathrm{~Hz})$; the subjects were allowed to adjust the tidal volume according to their own comfort.

Beat-to-beat values of systolic blood pressure and of inter-beat intervals were measured for further analysis. For the spectral analysis, the parameters were linearly interpolated and equidistantly sampled at $2 \mathrm{~Hz}$. The linear trend was removed. The autocorrelation and cross-correlation functions, power spectra and crossspectra, coherence and the modulus between inter-beat intervals and systolic blood pressure were calculated. The gain factor, i.e. the transfer function among variations in systolic blood pressure and inter-beat intervals, was calculated and its value at a frequency of $0.1 \mathrm{~Hz}$ was taken as a measure of BRS (Honzíková et al. 1992).

\section{Statistical analysis}

Mean values and standard deviations of BRS and BMI were calculated. The significance of the differences was evaluated by the Mann-Whitney test, and correlations were evaluated by Pearson's correlation 

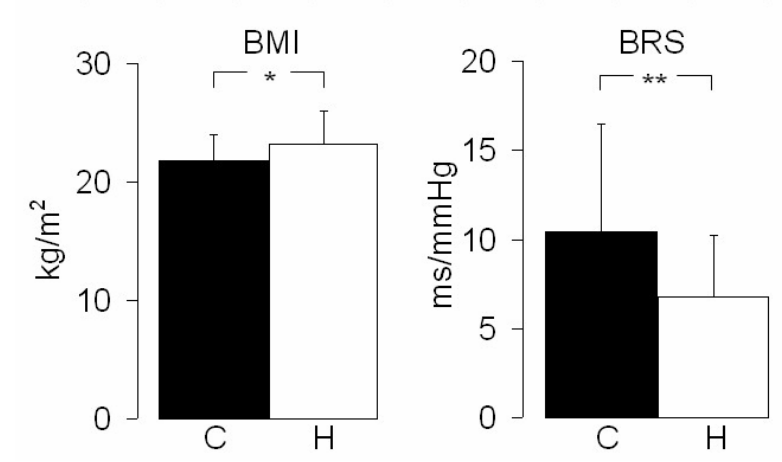

Fig. 1. Differences between body mass index (BMI) and baroreflex sensitivity (BRS) in healthy controls (C) and hypertensive subjects $(\mathrm{H})$; Mann-Whitney test, ${ }^{*} \mathrm{p}<0.05$, ** $\mathrm{p}<0.01$.

coefficient. The predicting power of BMI, BRS, and a combination of both factors for hypertension was evaluated by sensitivity and specificity. Optimal critical values were determined by receiver operating curve (ROC), i.e., a plot of sensitivity versus specificity for moving critical values in steps (Camm and Fei 1995).

The area under ROC (AUC) was taken as another index of predicting power for hypertension of both factors (Webb et al. 2005, Maloof 2002). Logistic regression analysis was applied for evaluation of association of decreased BRS and increased BMI with a risk of hypertension.

\section{Results}

Comparison of BRS and BMI showed that hypertensive subjects had significantly higher BMI and lower BRS compared with healthy adolescents (Table 1, Fig. 1). The relationship between BMI and BRS was analyzed using correlation analysis. No correlation between BMI and BRS was found either in hypertensive subjects or in controls (Fig. 2). In addition, multiple logistic regression analysis revealed that a low BRS $(\mathrm{p}<0.05)$ and an increased BMI $(\mathrm{p}<0.01)$ were independent variables associated with an increased risk of hypertension.

$\mathrm{Y}=4.01-0.23 * \mathrm{BMI}+0.19 * \mathrm{BRS} \quad(\mathrm{p}<0.001)$

For $\mathrm{C}=1 ; \mathrm{H}=0$

The significance of both factors for elevation of blood pressure was compared using calculation of sensitivity and specificity. It was necessary to know the critical values of both factors for predicting whether a subject should come under a group of normotensive or hypertensive subjects. Because a critical value either of

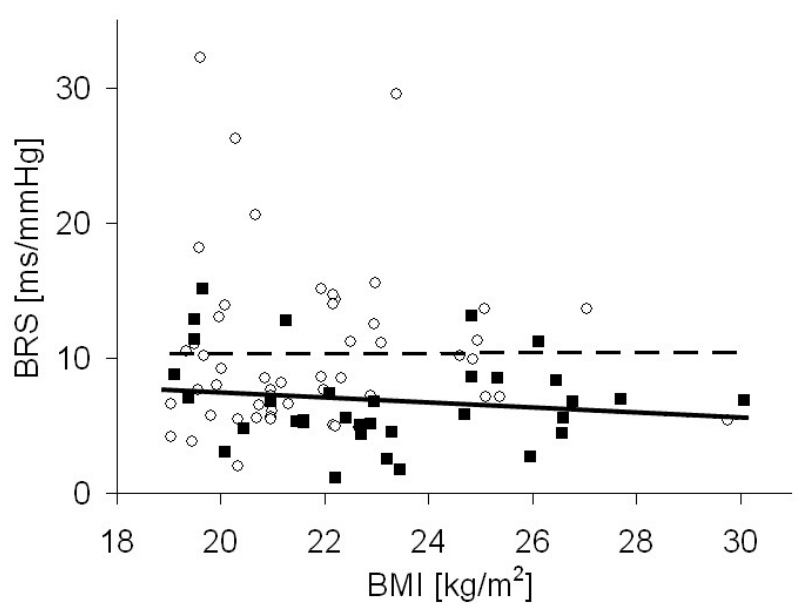

Fig. 2. Correlation between body mass index (BMI) and baroreflex sensitivity (BRS) in healthy controls (circles and dashed line) and hypertensive subjects (squares and full line); Pearson's correlation coefficients are insignificant (correlation coefficient in controls is 0.001 , in hypertensive subjects is - 0.153).

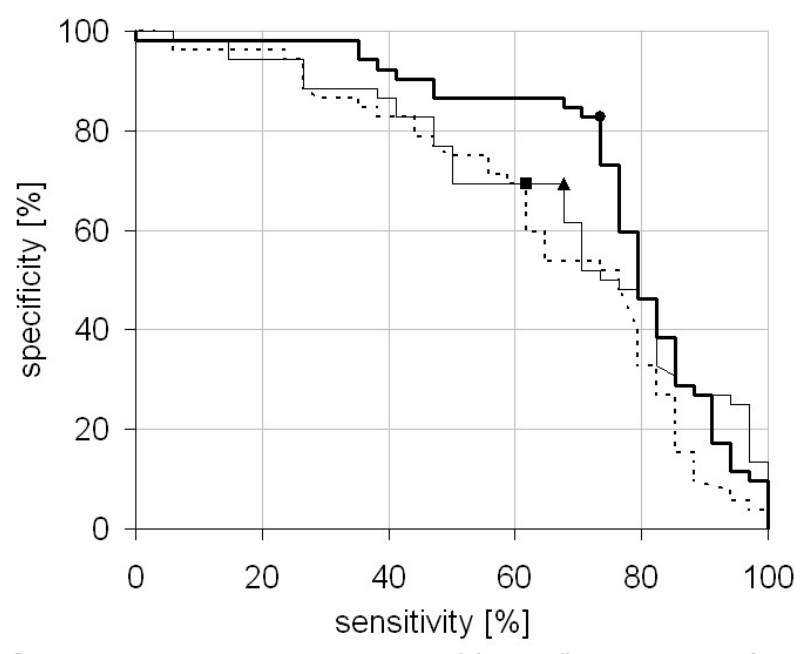

Fig. 3. Receiver operating curves of baroreflex sensitivity (BRS thin line), body mass index (BMI dashed line), and combination of both factors (full line). Optimal critical values determined as values at which maximum achievable combination of sensitivity and specificity was reached: $7.08 \mathrm{~ms} / \mathrm{mmHg}$ for BRS (triangle), $22.20 \mathrm{~kg} / \mathrm{m}^{2}$ for BMI (square), and 0.439 normalized units for combination of BMI and BRS (point).

BRS or of BMI for a risk of hypertension is not used as a standard, we have determined optimal critical values for BRS, BMI, and a combination of both factors by calculation sensitivity and specificity for moving critical values in steps and determining receiver operating curves (ROC, plot of sensitivity versus specificity, Fig. 3). Optimal critical values were determined as values at which the maximum achievable combination of sensitivity and specificity was reached: $7.08 \mathrm{~ms} / \mathrm{mmHg}$ for BRS, $22.20 \mathrm{~kg} / \mathrm{m}^{2}$ for BMI, and 0.439 normalized 
units for combination of BMI and BRS based on the logistic model. The area under receiver operating curve was used for comparison of the predicting power of BRS, BMI and a combination of both factors. Sensitivity, specificity and AUC of BRS, BMI, and combination of both factors showed an additive effect of both parameters on an increase of blood pressure (Table 2, Fig. 3).

\section{Discussion}

There is almost universal agreement that baroreflex control of heart rate (or R-R interval) is impaired in patients with hypertension, and that the degree of impairment is proportional to the degree of blood pressure elevation. The evidence that baroreflex abnormalities are implicated as factors that promote or perpetuate hypertensive processes is less strong.

Studies have also consistently shown that in the state of a developed hypertension in adults, a decrease of BRS is associated with an increase of the thickness of the carotid wall (Lábrová et al. 2005).

A different situation exists in early-stage hypertension in children and adolescents. Our study investigated whether a low BRS could be one of the individual factors resulting in an early blood pressure elevation. Our results show an additive affect of obesity and low BRS in the early stage of development of hypertension, when analyzed by correlation analysis and by calculation of sensitivity, specificity, and area under receiver operating curve for BMI, BRS, and a combination of BRS and BMI. These findings suggest that children with a primarily low BRS could have greater predisposition for pathological blood pressure elevation and therefore that from a preventive-treatment point of view their style of life should be more strongly controlled.

On the other hand, the association of a BRS decrease with obesity has been shown in many studies (Hubert et al. 1983, Gordon et al. 1997, Kriketos et al. 2001, Honzíková et al. 2006b). We emphasize that in our study we included children and adolescents with normal weight and overweight, but not with severe obesity. Thus we focused on the early stages of blood pressure elevation and of overweight development before the metabolic syndrome is fully developed and causes serious changes in vessels. This is why we also included the group of subjects with white coat hypertension among the hypertensive patients. Based on our previous study (Honzíková et al. 2006b) we assume white coat hypertension in adolescents to be an early stage in the development of elevated blood pressure. Since our tested group did not include subjects with heavy obesity, our results are parallel to those of Dietrich et al. (2006), who also did not find correlation between BRS and BMI in children having a normal weight or overweight. On the other hand, Dietrich et al. (2006) found a negative correlation between BRS and BMI in obese children.

It is not simple to explain the apparent finding that the decreased heart-rate BRS influences the elevation of blood pressure in a young population. It is necessary to take into account the hypothesis that the heart-rate BRS plays an important role in the buffering of blood pressure (Kardos et al. 1995). In accordance with this hypothesis, a decreased buffering capacity of heart rate on blood pressure could be a factor in the increased risk for sudden cardiac death in patients after myocardial infarction (LaRovere et al. 1998, Honzíková et al. 2000). In these patients, bradycardic response of heart rate as a reaction to sudden blood pressure increase not only decreases blood pressure, but it also decreases the energy demand of the heart and improves the conditions for perfusion of the coronary vessels. But what is role of a decreased BRS in development of hypertension? At present we can only speculate about this role. It is known that increased circadian variability is related to an increased thickness of intima-media of the common carotid artery and thus to development of hypertension (Sander and Klingelhofer, 1996, Zakopoulos et al. 2005). It has also been found that an increase of short-term blood pressure variability is associated with hypertension (Honzíková et al. 2006b). Moreover, a genetic study has found that people with genetically lower activity of eNOS have higher blood pressure variability (Jíra et al. 2006b). It seems likely that not only the increased blood pressure but also its increased variability can lead to a remodeling of an arterial wall, to an increase of vasomotor tone and to an elevation of blood pressure.

The assessment of critical values of tested parameters for differentiation between hypertensive patients and healthy subjects should be viewed as limited to designating the groups we examined. It is not possible to treat these parameters as generally valid values for determining at-risk subjects. To assess generally valid criteria, it would be necessary to examine large groups of adolescents, preferably within a multicentric study.

We conclude that there is likely a strong role of decreased BRS in the development of hypertension, although this role is as yet poorly understood. Based on 
our results, we suggest that decreased BRS may serve as a diagnostic indicator for detecting individuals among children and youth, for whom an accumulation of additional risk factors (obesity, lack of exercise, smoking) predisposes to the development of hypertension. In this case our study may have important implications for preventive medicine as well.

\section{Conflict of Interest}

There is no conflict of interest.

\section{Acknowledgements}

Supported by grants MSM: 0021622402 and 0021630529.

\section{References}

BENE J, HORAN MA, CLAGUE JE: Reproducibility of baroreflex sensitivity measured by a neck suction method. Clin Sci 96: 437, 1999.

CAMM AJ, FEI L. Risk stratification following myocardial infarction: Heart rate variability and other risk factors. In: Heart Rate Variability. M MALIK, AJ CAMM (eds), Armonk, New York, 1995, pp 369-372.

DIETRICH A, RIESE H, VAN ROON AM, VAN ENGELEN K, ORMEL J, NEELEMAN J, ROSMALEN GM: Spontaneous baroreflex sensitivity in (pre)adolescents. J Hypertens 24: 345-352, 2006.

GOLLASCH M, TANK J, LUFT FC, JORADAN J, MAASS P, KRASKO C, SHARMA AM, BUSJAHN A, BAHRING S: The BK channel $\beta 1$ subunit gene is associated with human baroreflex and blood pressure regulation. J Hypertens 20: 927-933, 2002.

GORDON NF, SCOTT CB, LEVINE BD: Comparison of single versus multiple lifestyle interventions: are the antihypertensive effects of exercise training and diet-induced weight loss additive? Am J Cardiol 79: 763-767, 1997.

GRIBBIN B, PICKERING TG, SLEIGHT P, PETO R: Effect of age and high blood pressure on baroreflex sensitivity in man. Circ Res 24: 424-431, 1971.

IWASE N, TAKATA S, OKUWA H, OGAWA J, IKEDA T, HATTORI N: Abnormal baroreflex control of heart rate in normotensive young subjects with a family history of essential hypertension. J Hypertens 2 (Suppl): S409S411, 1984.

HONZÍKOVÁ N, FIŠER B, HONZÍK J: Noninvasive determination of baroreflex sensitivity in man by means of spectral analysis. Physiol Res 41: 31-37, 1992.

HONZÍKOVÁ N, KRTIČKA A, NOVÁKOVÁ Z, ZÁVODNÁ E: A dampening effect of pulse interval variability on blood pressure variations with respect to primary variability in blood pressure during exercise. Physiol Res 52: 299-309, 2003.

HONZÍKOVÁ N, LÁBROVÁ R, FIŠER B, MADĚROVÁ E, NOVÁKOVÁ Z, ZÁVODNÁ E, SEMRÁD B: Influence of age, body mass index, and blood pressure on the carotid intima-media thickness in normotensive and hypertensive patients. Biomed Tech 51: 159-162, 2006a.

HONZÍKOVÁ N, NOVÁKOVÁ Z, ZÁVODNÁ E, PADĚROVÁ J, LOKAJ P, FIŠER B, BALCÁRKOVÁ P, HRSTKOVÁ H: Baroreflex sensitivity in children, adolescents, and young adults with essential and white-coat hypertension. Klin Padiatr 218: 237-242, 2006 b.

HONZÍKOVÁ N, SEMRÁD B, FIŠER B, LÁBROVÁ R: Baroreflex sensitivity determined by spectral method and heart rate variability, and two-years mortality in patients after myocardial infarction. Physiol Res, 49: 643-650, 2000.

HUBERT HB, FEINLEIB M, MCNAMARA PM, CASTELLI WP: Obesity as an independent risk factor for cardiovascular disease: a 26-year follow-up of participants in the Framingham Heart Study. Circulation 67: 968-977, 1983.

JÍRA M, ZÁVODNÁ E, HONZÍKOVÁ N, NOVÁKOVÁ Z, FIŠER B: Baroreflex sensitivity as an individual characteristic feature. Physiol Res 53: 349-351, 2006a.

JÍRA M, ZÁVODNÁ E, HONZÍKOVÁ N, NOVÁKOVÁ Z, VAŠKŮ A, IZAKOVIČOVÁ HOLLÁ L, ZNOJIL V, FIŠER B: Association of eNOS gene polymophisms T-786C and G894T with blood pressure variability. Physiol Res 55: 26P, 2006b. 
KARDOS A, RUDAS L, GINGL Z, SZABADOS S, SIMON J: The mechanism of blood pressure variability: Study in patients with fixed ventricular pacemaker rhythm. Eur Heart $J$ 16: 545-52, 1995.

KARDOS A, WATTERICH G, DE MENEZES R, CSANADY M, CASADEI B, RUDAS L: Determinants of spontaneous baroreflex sensitivity in a healthy working population. Hypertension 37: 911-916, 2001.

KRIKETOS AD, ROBERTSON RM, SHARP TA, DROUGAS H, REED GW, STORLIEN LH, HILL JO: Role of weight loss and polyunsaturated fatty acids in improving metabolic fitness in moderate obese, moderately hypertensive subjects. J Hypertens 19: 1745-1754, 2001.

LA ROVERE MT, BIGGER JT, MARCUS FI, et al: Baroreflex sensitivity and heart-rate variability in prediction of total cardiac mortality after myocardial infarction. ATRAMI (Autonomic tone and reflexes after myocardial infarction) investigators. Lancet 351: 478-484, 1998.

LÁBROVÁ R, HONZÍKOVÁ N, MADĚROVÁ E, VYSOČANOVÁ P, NOVÁKOVÁ Z, ZÁVODNÁ E, FIŠER B, SEMRÁD B: Age-dependent relationship between the carotid intima-media thickness, baroreflex sensitivity, and the inter-beat interval in normotensive and hypertensive subjects. Physiol Res 54: 593-600, 2005.

LURBA E, ALVAREZ V, LIAO Y, TACONS J, COOPER R, CREMADES B, TORRO I, REDON J: The impact of obesity and body fat distribution on ambulatory blood pressure in children and adolescents. Am J Hypertens 11: 418-424, 1998.

MALOOF MA: On Machine Learning, ROC Analysis, and Statistical Tests of Significance. Pattern Recogn 12: 204207, 2002.

SANDER D, KLINGELHOFER J: Diurnal systolic blood pressure variability is the strongest predictor of early carotid atherosclerosis. Neurology 47: 500-507, 1996.

SOERGEL M, KIRSCHSTEIN M, BUSCH CH, KANNE T, GELLERMANN J, HALL R, KRULL F, REICHERT H, REUSZ GS, RASCHER W: Oscillometric twenty-four-hour ambulatory blood pressure values in healthy children and adolescents. A multicenter trial including 1141 subjects. J Pediatr 130: 178-184, 1997.

TANK J, JORDAN J, DIETRICH A, STOFFELS M, FRANKE G, FAULHABER HD, LUFT FC, BUSJAHN A: Genetic influences on baroreflex function in normal twins. Hypertension 37: 907-910, 2001.

TASK FORCE ON BLOOD PRESSURE CONTROL IN CHILDREN: Update on the 1987 task force report on high blood pressure in children and adolescents: A Working Group Report from the National High Blood Pressure Education Program. National High Blood Pressure Education Program Working Group on Hypertension Control in Children and Adolescents. Pediatrics 98: 649-58, 1996.

URBINA EM, SRINIVASAN SR, KIELTYKA RL, TANG R, BOND MG, CHEN W, BERENSON GS: Correlates of carotid artery stiffness in young adults: The Bogalusa heart study. Atherosclerosis 176: 157-164, 2004.

VOS LE, OREN A, BOTS ML, ET AL: Does a routinely measured blood pressure in young adolescence accurately predict hypertension and total cardiovascular risk in young adulthood? J Hypertens 21: 2027-2034, 2003.

WEBB G, TING KM: On the application of ROC analysis to predict classification performance under varying class distributions. Mach Learn 58: 25-32, 2005.

ZAKOPOULOS NA, TSIVGOULIS G, BARLAS G, PAPAMICHAEL C, SPENGOS K, MANIOS E, ET AL: Time rate of blood pressure variation is associated with increased common carotid artery intima-media thickness. Hypertension 45: 505-512, 2005.

ZANCHETI A, BOND MG, HENNING M, NEISS A, MANCIA G, PALU CD, HANSSON L, MAGNANI B, RAHN KH, REID J, RODICIO J, SAFAR M, ECKES L, RAVINETTO R: Risk factors associated with alterations in carotid intima-media thickness in hypertension: baseline data from European Lacidipine Study on Atherosclerosis. J Hypertens 16: 949-961, 1998.

ZÁVODNÁ E, HONZÍKOVÁ N, HRSTKOVÁ H, NOVÁKOVÁ Z, MOUDR J, JÍRA M, FIŠER B: Can we detect the development of baroreflex sensitivity in humans between 11 and 20 years of age? Can J Physiol Pharmacol 84: 1275-1283, 2006. 